(2) Open Access Full Text Article

REVIEW

\title{
Assessment of quality of life in veterinary practice: developing tools for companion animal carers and veterinarians
}

This article was published in the following Dove Press journal:

Veterinary Medicine: Research and Reports

21 May 2015

Number of times this article has been viewed

\section{Siobhan Mullan}

Department of Clinical Veterinary

Science, University of Bristol

Veterinary School, Bristol, UK
Correspondence: Siobhan Mullan

Department of Clinical Veterinary Science, University of Bristol Veterinary

School, Langford House, Langford,

Bristol BS40 5DU, UK

Tel +440II79289484

Email siobhan.mullan@bristol.ac.uk
Abstract: Quality-of-life assessments aim to provide an all-encompassing evaluation of animal welfare. In comparison to more limited, disease-focused welfare assessments, they have the potential to better identify welfare deficiencies, allowing veterinarians to target improvement strategies for greater benefit. Individuals or populations of companion animals may be assessed and carers and/or veterinarians may contribute to the assessment. Quality-of-life assessments are widely used within the human health care setting, and although the number of veterinary assessment tools is substantially fewer, these tools cover a range of methodologies. Further research to validate existing tools and develop new ones is recommended. Guidance for implementing and evaluating the usefulness of quality-of-life assessment tools within companion animal veterinary clinics is presented.

Keywords: quality of life, welfare, companion animals, veterinary practice, evidence-based veterinary medicine

\section{Introduction}

"How will I know when my dog is suffering too much and it's time to call it a day?"; "Does my guinea pig really need a companion?"; and "I just don't know whether I should put my cat through it." These are all familiar phrases and questions from clients in companion animal practice. All these are contemplating the quality of life of their companion animal in different ways, to make decisions about clinical care, euthanasia, and home care. Indeed, caring for the animal a person owns best characterizes the human-companion animal relationship and, therefore, carer seems a more appropriate term for an "owner." Clinical veterinarians might also ask questions about the quality of life of the animals under their care: "Which type of congestive cardiac failure management has the best overall outcome?"; "Should I insist on cage rest for this dog?"; "What should I target to bring about the biggest improvement in the welfare of all the animals that come to the clinic?"; and "Which animals at the clinic are most at risk of poor welfare in the future?"

To answer these questions so as to promote the welfare of companion animals by providing good guidance for clients, it is necessary to first understand what quality of life is, how best to assess it, and what to do with the information.

\section{What is quality of life?}

Quality of life of animals is considered in this article to be synonymous with the term "welfare" and has been widely discussed as being dependent on one's philosophical 
viewpoint and may both influence, and be influenced by, scientific research..$^{1-5}$ However, there is a consensus that the term "quality of life" refers to much more than simply health. One proposal is that quality of life encompasses three elements: 1) positive and negative feelings (the experiences felt by animals, which are on a spectrum ranging from very negative (eg, severe pain) to very positive (eg, playfulness); 2) physical fitness and health (encompassing elements such as challenge posed by diseases, ability to reproduce, and an animal's physical ability to cope with its environment); and 3) naturalness (existing in a natural physical form, free from mutilations or extremely unnatural body shapes, with the ability to carry out natural behaviors and experience elements of natural environments), to which different people ascribe weight to varying degrees. ${ }^{6}$ When asked about a definition of farm animal welfare, conventional farmers tend to place more weight on physical fitness, welfare scientists on feelings, and other societal members on naturalness than each of the other groups $;{ }^{7,8}$ however, little is known about how carers and others involved with companion animals view welfare. That there is no societal consensus on the relative importance of each element opens up the potential for disagreements among people, even when they share a common aim of improving or protecting welfare. For example, a client who values naturalness highly may be less inclined towards euthanasia, seen as an "unnatural" intervention, than a veterinarian who puts greater weight on physical health and negative mental feelings; yet, both are aiming to do the right thing at the end of life.

The World Health Organization (WHO) has developed a holistic (ie, covering all aspects of life) cross-cultural quality-of-life assessment that encompasses six domains subdivided into 24 facets, giving an indication of the elements they consider make up quality of life in people. Many of these facets are readily applicable to animals, such as "energy and fatigue," while others may not be, such as "bodily image and appearance" (Table 1). The questionnaire associated with the assessment underwent extensive initial validation, ${ }^{9}$ along with a shorter version, ${ }^{10,11}$ and has been used very widely around the world since. Often, qualityof-life assessments of people just focus on the elements or domains affected by health and then use the term "healthrelated quality of life," although these too tend to include very broad domains when making general assessments. For example, the Patient Reported Outcomes Measurement Information System health-related quality-of-life assessment has been built only upon three of the WHO domains, calling them physical health, mental health, and social health. ${ }^{12}$
Table I WHOQOL domains and facets that may be applicable to animals

\begin{tabular}{|c|c|c|}
\hline \multirow{2}{*}{$\begin{array}{l}\text { WHOQOL } \\
\text { domains }\end{array}$} & \multicolumn{2}{|c|}{ Facets incorporated within domains } \\
\hline & $\begin{array}{l}\text { Facets that may be } \\
\text { applicable to animals }\end{array}$ & $\begin{array}{l}\text { Facets that may } \\
\text { not be applicable } \\
\text { to animals }\end{array}$ \\
\hline Physical health & $\begin{array}{l}\text { Energy and fatigue } \\
\text { Pain and discomfort } \\
\text { Sleep and rest }\end{array}$ & \\
\hline $\begin{array}{l}\text { Psychological } \\
\text { health }\end{array}$ & $\begin{array}{l}\text { Negative feelings } \\
\text { Positive feelings } \\
\text { Thinking, learning, memory, } \\
\text { and concentration }\end{array}$ & $\begin{array}{l}\text { Bodily image and } \\
\text { appearance } \\
\text { Self-esteem }\end{array}$ \\
\hline $\begin{array}{l}\text { Level of } \\
\text { independence }\end{array}$ & $\begin{array}{l}\text { Mobility } \\
\text { Activities of daily living } \\
\text { Dependence on medicinal } \\
\text { substances and medical aids }\end{array}$ & Work capacity \\
\hline $\begin{array}{l}\text { Social } \\
\text { relationships }\end{array}$ & $\begin{array}{l}\text { Personal relationships } \\
\text { Social support } \\
\text { Sexual activity }\end{array}$ & \\
\hline Environment & $\begin{array}{l}\text { Freedom, physical safety, } \\
\text { and security } \\
\text { Health and social care: } \\
\text { accessibility and quality } \\
\text { Home environment } \\
\text { Opportunities for acquiring } \\
\text { new information and skills } \\
\text { Participation in and } \\
\text { opportunities for } \\
\text { recreation/leisure } \\
\text { Physical environment } \\
\text { (pollution/noise/traffic/ } \\
\text { climate) } \\
\text { Transport }\end{array}$ & Financial resources \\
\hline
\end{tabular}

Spirituality/religion/

Religion/spirituality/ personal beliefs personal beliefs

Abbreviation: WHOQOL, World Health Organization Quality of Life.

\section{Why assess quality of life in companion animals?}

We have seen already that there are common and pertinent questions in companion animal practice that require an assessment of quality of life to determine the best course of action. In addition, clients and veterinarians have been answering these questions to the best of their ability since the inception of veterinary practice. They have drawn upon their previous experience, scientific knowledge, and empathy to make these judgments in an informal way. The question really is what can be gained through formal, systematic assessment of quality of life within companion animal practice.

\section{Quality-of-life assessments within research}

The use of quality-of-life assessments within clinical research studies, especially in clinical research, could aid clinical decision making through the provision of more patient-centered 
relevant information about outcomes rather than outcomes with a narrow clinical focus. The onus here is on researchers to include such assessments in their evaluations so clinicians have the best information available to them to make, or facilitate carers to make, better decisions. In human medical research, there has been a clear shift from more blunt measures of efficacy, such as survival times, to those that include an adjustment for quality of life, ${ }^{13}$ and this concept has been formalized into health care policy through use of an estimation of "quality-adjusted life years," or QALYs, to guide decisions about cost-effectiveness of treatments in the UK health service. ${ }^{14}$

Quality-of-life assessments have been found to be valuable prognostic indicators for humans with a range of diseases. Using colorectal cancer as an example, qualityof-life assessment independently predicted mortality in patients with advanced disease ${ }^{15}$ and was a better predictor of survival for patients with liver metastases than tumor size. ${ }^{16}$ Earlam et $\mathrm{al}^{16}$ suggested that the quality-of-life information could be used "as a surrogate end point in treatment trials" for colorectal cancer. Similarly, quality-of-life assessments have been found to be better, or independent, prognostic indicators than traditional disease-focused assessments for various types of cancers (eg, prostate ${ }^{17}$ and breast cancers ${ }^{18}$ ) and heart disease, ${ }^{19}$ among others.

\section{Quality-of-life assessments of individual patients}

Use of quality-of-life assessments to guide individual care of veterinary patients may enable identification of areas for improvement in terms of quality of life, areas that might otherwise be overlooked. Centering quality-of-life assessment on individual care and improvement has been a more recent development in human health care than population investigations. Some studies have found clear patient benefits to assessing the quality of life of individual patients, eg, in the area of mental health, ${ }^{20}$ yet reviews have suggested that while there are potential benefits, these have not always been demonstrated. ${ }^{21-24}$ One study that used specialist nurses to interview oncology patients using validated quality-of-life tools and to then report these back to the patients' attending nurses found that this process made no difference in patient-reported quality of life or satisfaction 6 months later compared to a control group. ${ }^{25}$ The authors suggest that assessment alone is not enough and that "positive effects may require supplementing assessment results with specific suggestions for clinical management changes." 25
Decisions relating to euthanasia of animals are a natural extension of assessments to aid clinical decision making seen in humans, although decisions in people about when to change from active treatment to palliative care may be similar. Such an important decision as euthanasia is unlikely to be defined by a stark calculation, a single number resulting from a formal quality-of-life assessment, but a wide consideration of all the elements of an animal's life, beyond the disease itself, could be beneficial. In this situation, the quality-of-life assessment could act more as a checklist to ensure consideration of positive experiences as well as a wider range of negative experiences other than pain, such as nausea or inability to enjoy social contact. There are several unvalidated suggestions for quality-of-life assessments to aid carers in their euthanasia decisions on popular Web sites, but their usefulness has not been evaluated. ${ }^{26,27}$

\section{Quality-of-life assessment of populations of companion animals}

Systematically conducted holistic welfare screening assessments could be used to stimulate improvements in the quality of life of the veterinary clinic's companion animal population. Through encouraging carers to report and discuss a wide range of quality-of-life issues, it could serve to highlight areas in which quality of life could be improved. In the human health care setting, there have been perceived benefits from identifying quality-of-lifeimpacting situations, including disorders that were not originally presented to the clinician (such as anxiety, ${ }^{28}$ risk factors for diseases, eg, in older people ${ }^{29}$ ) or screening for elements outside a disease-focused consultation, such as intimate partner violence. ${ }^{30} \mathrm{In}$ animals there may be additional welfare benefits achieved via veterinary practice through screening for a wide range of disease conditions, as well as evaluating the care provided to the animal and the effects of that care on the animal. This use of quality-of-life assessment, if used to stimulate changes to the care of the companion animal, that have a substantial and prolonged effect, may result in the greatest overall improvement in the welfare of the population of animals visiting the clinic. For example, providing a compatible rabbit as a companion to an existing solitary rabbit could have a marked positive effect $^{31}$ that is continuous and lasts for many years, whereas improvements to clinical decision making affect only a few animals, often for a relatively short amount of time. In addition, holistic quality-of-life assessment tools may be able to help prevent future poor welfare by identifying risk factors for both disease and other elements of poor 
welfare, thus enabling targeted support for clients to make relevant changes.

\section{Measures of quality of life in companion animals}

Within the chosen ethical framework of welfare, there are many decisions to be made about the measures of quality of life that are used in companion animals. Although some measures may be relevant to all species, such as pain, the method of assessment may need to vary depending on the type of expression that each species favors. For example, there are detailed pain-scoring systems that vary considerably in their content for a range of companion animal species, such as dogs, ${ }^{32}$ cats, ${ }^{33}$ rabbits, ${ }^{34}$ rats,,${ }^{35}$ and mice. ${ }^{36}$ A holistic qualityof-life assessment should aim to cover the spectrum of experiences and opportunities for animals, from negative to positive. That way, important elements are not underrepresented in the assessment. To best improve welfare, much research attention has to date focused on understanding the welfare significance, risk factors, and indicators of poor welfare in animals. Now, however, we are gaining insight into the positive experiences of animals and are developing methods for assessing those, ${ }^{37}$ eg, through behavioral observations, ${ }^{38}$ tests such as cognitive bias, ${ }^{39}$ or assessment of opportunities for animals to choose positive experiences. ${ }^{40} \mathrm{McMillan}^{41}$ also suggests that maximizing control, or autonomy, is important for animal welfare and should be included in quality-of-life assessments.

\section{Quality of life methods of assessment: comparison and evaluation Type of assessment}

Although far behind the human literature, a number of qualityof-life assessment tools have been developed for companion animals. Christiansen and Forkman ${ }^{42}$ reviewed 32 of the earlier tools that used the terms "animal welfare," "quality of life," or "well-being" in evaluating veterinary treatment outcomes. They found that most were concerned with health-related measures of quality of life, usually specific to the disease of concern, although some of the behavioral assessments had potential for interpreting signs of wider welfare interest. They categorized the questions in terms of clinical aspects (mortality, treatment, implications, and pain) and general welfare (social behavior, functionality, and mental state). Questions about overall welfare were present in ten studies, sometimes as the only wider welfare indicator. The authors strongly recommend that this type of quality-of-life assessment be widened to include more measures of welfare, which they suggest may need the help of ethologists to achieve.
One health-related quality-of-life assessment tool that was initially developed to assess chronic pain in dogs used 109 simple descriptor seven-point Likert scales relating to both physical and mental states, including broader behavioral observations. ${ }^{43}$ Mullan and Main ${ }^{44}$ adapted the assessment method of Wiseman-Orr et $\mathrm{al}^{43}$ for use as a companion animal practice screening tool to identify areas of welfare improvement. They also included questions about resources offered to the dogs and an estimation of whether the dogs would choose other provisions. ${ }^{44}$ The resources offered to dogs formed the basis for one welfare assessment designed by Wojciechowska et al to complement the physical examination provided by a veterinary surgeon. ${ }^{45}$

\section{Who makes the assessment}

All bar one of the assessments reviewed by Christiansen and Forkman ${ }^{42}$ used carer reporting, sometimes in conjunction with a veterinary assessment. Carers have the advantage that, in general, they know their own companion very well, especially when in their home environment, and are likely to be able to detect even small changes from the normal or best situation the dog has been in. This was captured in the quality-of-life screening tool of Mullan and Main ${ }^{44}$ by asking carers to rate on visual analog scale points corresponding to their dog "at the moment" and also "when at their best." Carers are often deeply concerned about the welfare of their companion animal and therefore are assumed to try to answer questions accurately. However, carers may feel pressurized to provide certain answers or may exhibit unconscious biases. For example, carers may not have experienced a wide range of welfare of companion animals, such as when their companion animal has always been lonely or never been sick, or they may not easily identify clinical or behavioral signs. ${ }^{46}$ Veterinarians may also not be able to detect some, particularly behavioral, signs well ${ }^{42}$ and may be seeing the animals in an unfamiliar environment. However, they have been trained to observe clinical signs and ask clinically relevant questions that may provide additional beneficial information to an assessment.

\section{Scoring methods}

Some assessments produce an overall score that can be used to compare individuals over time or populations of animals. ${ }^{47,48}$ For example, one tool used to assess the quality of life of dogs with cancer pain contained 12 questions, each with a 0 - to 3-point scale for an answer and an overall maximum score of $36 .{ }^{49}$ Determining a weighting for the scoring system could be done by utilizing expert opinion in more or less formal ways ${ }^{50}$ or, as developed by Budke et al, ${ }^{51}$ through 
using carer ratings of the relative importance of the elements of their quality-of-life assessment tool for dogs with spinal injuries. It could be that some elements should "trump" others within an assessment in certain situations. For example, a very high pain score might be so overwhelming as to render other elements of quality of life unimportant. Assessments may also use scores that remain unaggregated, still allowing for individual elements to be compared over time or among animals, ${ }^{44}$ or even use elements or whole assessments that take a qualitative rather than a quantitative approach. ${ }^{52}$

\section{Validation}

Validation of quality-of-life tools for companion animals has been far less extensive than studies involving human assessment methods but nevertheless has occurred in a number of ways. Many assessment tools underwent construct validity testing and refinement by removing items that did not provide valuable information. ${ }^{45,53}$ Some assessment tools have been evaluated for test-retest repeatability by raters within a short time $\operatorname{span}^{44,45}$ or for interobserver reliability. ${ }^{51}$ Others have attempted to validate the tool for discriminatory ability between two populations of animals. Wiseman-Orr et $\mathrm{al}^{54}$ found differences in scores obtained by dogs with chronic pain compared to dogs without pain, whereas the resourcebased tool developed by Wojciechowska et $\mathrm{al}^{48}$ was unable to discriminate between sick and healthy dogs. Further refinement of the Wiseman-Orr et al $^{54}$ tool resulted in a general health-related quality-of-life assessment that was able to detect improvements in quality-of-life scores in previously obese dogs that lost weight. ${ }^{55}$ Other assessment methods have compared quality-of-life results with existing clinical scales relevant to the disease of interest..$^{47,53,56,57}$ Finally, the use of one quality-of-life assessment tool during veterinary canine consultations was associated with an increase in discussions about quality-of-life elements with the carer when used by a clinician familiar with the tool compared with a control group. ${ }^{58}$

\section{Quality-of-life assessment for carers and veterinarians: why we need new tools}

To return to the original question about the value of formal systematic assessment of quality of life in companion animal practice, it should be noted that such quality-of-life assessment has been widely adopted by, and is now integrated into, all aspects of human health care. One database has $>700$ different clinical outcome assessments available for a whole host of medical conditions. ${ }^{59}$ It can be inferred from drawing parallels with the human setting that there would be as-yet untapped benefits from formal quality-of-life assessments in companion animal practice, not only to individual patients but also to populations of animals and to carers and clinicians. Veterinary development of quality-of-life assessments is lagging behind but now has the ability to learn from the human field. There are few validated assessment tools available for companion animal practice although they represent a range of methodologies. The potential for quality-of-life tools to aid the very essence of all veterinary practice, namely improving the welfare of the animals that attend the clinic, means that these existing tools should be built upon, refined, and tested. In parallel, new tools need to be developed, aiming to capture the full range of experiences of companion animals over time. However, we do not just need new tools. Veterinarians are increasingly demanding an evidence base for their actions and could participate in such evaluations in their clinics. They will need training in how best to choose and use appropriate tools for their individual purposes.

\section{Implementation in the veterinary clinic}

The use of quality-of-life assessments within the veterinary clinic requires a degree of consideration and planning before implementation. That there is a lack of information regarding positive outcomes of using many of the veterinary assessment tools is regrettable, but this need not be a barrier to implementation, assuming there are unlikely to be negative consequences from such an implementation. Indeed, working on the principle that something is better (or at least equal to) nothing, if veterinary clinics are able to contribute to the knowledge base on efficacy of quality-of-life assessment to improve welfare overall, this is welcomed.

The International Society for Quality of Life Research in humans has produced useful guidance on implementing patient-reported outcomes in clinical practice, which are equally applicable to the veterinary setting (Table 2$).{ }^{60}$ The relative importance of each of the steps in achieving the welfare gains anticipated through formal, systematic assessment of companion animal quality of life is not yet known. For example, just using broad open questions pertinent to a holistic concept of animal welfare has been discussed as a method of quality-of-life assessment ${ }^{52}$ and could be achieved through implementing Steps 1-4. Whether this is effective at all, as well as whether there are additional benefits to quantitative scoring, reviewing scores at an individual or population level to enable interpretation (Step 5), or reporting scores 
Table 2 Application of the ISOQOL guidance on implementing patient-reported outcomes in clinical practice to companion animal veterinary practice

I. Identify the goals for collecting quality-of-life assessment information in clinical practice

For example, is the assessment aiming to screen for welfare deficiencies to be targeted for improvement among the whole clinic population or for monitoring the progress of individual patients?

2. Select the patients, setting, and timing of assessments

A tool could be used on all of the clinic's companion animal population or just for certain species or groups of animals such as hospitalized patients. Will the assessment occur at the time of the visit to the clinic or would it be sent to carers beforehand?

3. Determine which questionnaire(s) to use

Here the term "questionnaire" can be interpreted broadly to range from asking a few open verbal questions to a lengthier written or electronic format with or without quantitative scoring. Depending on the desired focus of assessment and response format, choosing a published assessment tool that has demonstrated some degree of peer review and validation is desirable. However, if there is not one available, then it is reasonable to devise one appropriate to need, with reference to human and veterinary literature. Amalgamating elements from a variety of existing tools may also prove useful.

4. Choose a mode for administering and scoring the questionnaire For example, will carers fill in the assessment before seeing a veterinarian or nurse? Where will they do this? Will they have time and space to complete the assessment - on paper or electronically? Or will the veterinary team interview carers and/or make their own assessments?

5. Design processes for reporting results

This is an important step to be clear on before implementing an assessment program. The person responsible for receiving and subsequently reporting the reports, as well as how this process will fit into the clinical workflow pattern, will need to be determined. This could depend on how quickly the report is required but, particularly with electronic capture, it may be possible to have immediate formatted reporting within the time of the veterinary consultation.

6. Identifying aids to facilitate score interpretation

To interpret quantitative results, clinicians may be guided by comparisons either with scores derived during assessments of the same animal at different time points or against scores from wider populations. Whereas for human quality-of-life assessment tools, there may be research studies that generated reference scores for similar patients or the general population, initially at least, it is likely that comparisons will be generated from the using practice's own data.

7. Develop strategies for responding to issues identified by the questionnaires

Without compromising the autonomy of the clinician, who usually has to integrate information from a range of sources, guidance on how best to respond to the welfare issues raised during the assessment may help to encourage steps along the path from assessment to quality-of-life improvement.

8. Evaluating the impact of the intervention on the practice

Even informal small-scale evaluations, such as discussion at practice meetings, can be useful, eg, if aiming to improve the usefulness of the assessment. Further low-cost/short-time evaluations such as carer or veterinary staff surveys, or analysis of samples of data, should be possible within veterinary clinics. Larger-scale evaluations, eg, with "control" groups, may require greater investment in time, money, and particularly expertise, but these should be undertaken, where possible, eg, in collaboration with a University.

Note: Data from Snyder et al. ${ }^{60}$

Abbreviation: ISOQOL, International Society for Quality of Life Research.

back to carers (Step 6) has not been studied in the veterinary context. Whatever form the assessment takes, it would seem important to support clinicians in facilitating carers to find solutions to improve welfare (Step 7) and to evaluate the whole process (Step 8).

\section{Conclusion and recommendations}

Companion animal quality-of-life assessment tools suitable for use in a veterinary clinic have been developed for a variety of purposes, such as to screen for issues suitable to target for welfare improvement, to evaluate interventions in a group of animals, or to monitor individual patients. That quality-of-life assessment tools have been so widely developed for use in humans around the world signals to us that a broad formal assessment of welfare and patient outcomes is likely to be beneficial. We need further research in this area to develop and evaluate new tools. We also need clinicians to embrace the concept of quality-of-life assessment and pioneer the implementation of such assessments within their clinics as another tool in the box aimed at achieving the ultimate goal of veterinary practice - improving the welfare of animals.

\section{Acknowledgments}

The author thanks David Main for his stimulating discussions about quality of life of animals and his constructive comments on the manuscript.

\section{Disclosure}

The author reports no conflicts of interest in this work.

\section{References}

1. Fraser D. Assessing animal welfare at the farm and group level: the interplay of science and values. Anim Welf. 2003;12(4):433-443. 
2. Appleby MC, Sandoe P. Philosophical debate on the nature of wellbeing: implications for animal welfare. Anim Welf. 2002;11(3): 283-294.

3. Sandoe P, Christiansen SB, Appleby MC. Farm animal welfare: the interaction of ethical questions and animal welfare science. Anim Welf. 2003;12(4):469-478.

4. Webster J. Animal Welfare: Limping Towards Eden. Oxford, UK: Blackwell; 2005 .

5. Dawkins MS. The science of animal suffering. Ethology. 2008;114(10): 937-945.

6. Fraser D, Weary DM, Pajor EA, Milligan BN. A scientific conception of animal welfare that reflects ethical concerns. Anim Welf. 1997;6(3): $187-205$.

7. Kling-Eveillard F, Dockes AC, Souquet C. Attitudes of French pig farmers towards animal welfare. Br Food J. 2007;109(11):859-869.

8. Prickett RW, Norwood FB, Lusk JL. Consumer preferences for farm animal welfare: results from a telephone survey of US households. Anim Welf. 2010;19(3):335-347.

9. Power M, Kuyken W, Orley J, et al. The World Health Organization Quality of Life assessment (WHOQOL): development and general psychometric properties. Soc Sci Med. 1998;46(12):1569-1585.

10. Harper A, Power M, Grp W. Development of the World Health Organization WHOQOL-BREF quality of life assessment. Psychol Med. 1998;28(3):551-558.

11. Skevington SM, Lotfy M, O'Connell KA. The World Health Organization's WHOQOL-BREF quality of life assessment: psychometric properties and results of the international field trial - a report from the WHOQOL group. Qual Life Res. 2004;13(2):299-310.

12. Cella D, Yount S, Rothrock N, et al; PROMIS Cooperative Group. The Patient-Reported Outcomes Measurement Information System (PROMIS) progress of an NIH roadmap cooperative group during its first two years. Med Care. 2007;45(5):S3-S11.

13. Billingham LJ, Abrams KR. Simultaneous analysis of quality of life and survival data. 2002;11(1):25-48.

14. NICE. Measuring Effectiveness and Cost Effectiveness: The QALY; 2010. Available from: https://www.nice.org.uk/proxy/?sourceurl=http:/ www.nice.org.uk/newsroom/features/measuringeffectivenessandcosteffectivenesstheqaly.jsp. Accessed February 4, 2015.

15. Wong CKH, Law W-L, Wan Y-F, Poon JT-C, Lam CL-K. Health-related quality of life and risk of colorectal cancer recurrence and All-cause death among advanced stages of colorectal cancer 1-year after diagnosis. BMC Cancer. 2014;14:337.

16. Earlam S, Glover C, Fordy C, Burke D, AllenMersh TG. Relation between tumor size, quality of life, and survival in patients with colorectal liver metastases. J Clin Oncol. 1996;14(1):171-175.

17. Braun DP, Gupta D, Staren ED. Predicting survival in prostate cancer: the role of quality of life assessment. Support Care Cancer. 2012;20(6): 1267-1274.

18. Staren ED, Gupta D, Braun DP. The prognostic role of quality of life assessment in breast cancer. Breast J. 2011;17(6):571-578.

19. Lim LLY, Johnson NA, O'Connell RL, Heller RF. Quality of life and later adverse health outcomes in patients with suspected heart attack. Aust N Z J Public Health. 1998;22(5):540-546.

20. Pitkanen A, Hatonen H, Kuosmanen L, Valimaki M. Individual quality of life of people with severe mental disorders. J Psychiatr Ment Health Nurs. 2009;16(1):3-9.

21. Lindblad AK, Ring L, Glimelius B, Hansson MG. Focus on the individual - quality of life assessments in oncology. Acta Oncol. 2002;41(6): 507-516.

22. Greenhalgh J. The applications of PROs in clinical practice: what are they, do they work, and why? Qual Life Res. 2009;18(1):115-123.

23. Valderas JM, Kotzeva A, Espallargues M, et al. The impact of measuring patient-reported outcomes in clinical practice: a systematic review of the literature. Qual Life Res. 2008;17(2):179-193.

24. Marshall S, Haywood K, Fitzpatrick R. Impact of patient-reported outcome measures on routine practice: a structured review. J Eval Clin Pract. 2006;12(5):559-568.
25. Rosenbloom SK, Victorson DE, Hahn EA, Peterman AH, Cella D Assessment is not enough: a randomized controlled trial of the effects of HRQL assessment on quality of life and satisfaction in oncology clinical practice. Psychooncology. 2007;16(12):1069-1079.

26. Hilst K. Quality of Life Scale for Pets; 2015. Available from: http:// www.hilstvet.com/quality-of-life-scale-pets/. Accessed February 4, 2015.

27. Villalobos A. Quality of Life Scale; 2011. Available from: http:// pawspice.com/q-of-1-care/new-page.html. Accessed May 11, 2015.

28. Kroenke K, Spitzer RL, Williams JBW, Monahan PO, Lowe B. Anxiety disorders in primary care: prevalence, impairment, comorbidity, and detection. Ann Intern Med. 2007;146(5):317-325.

29. Goldberg TH, Chavin SI. Preventive medicine and screening in older adults. J Am Geriatr Soc. 1997;45(3):344-354.

30. Nelson HD, Bougatsos C, Blazina I. Screening women for intimate partner violence: a systematic review to update the US preventive services task force recommendation. Ann Intern Med. 2012;156(11):796.

31. Chu LR, Garner JP, Mench JA. A behavioral comparison of New Zealand White rabbits (Oryctolagus cuniculus) housed individually or in pairs in conventional laboratory cages. Appl Anim Behav Sci. 2004; 85(1-2):121-139.

32. Firth AM, Haldane SL. Development of a scale to evaluate postoperative pain in dogs. J Am Vet Med Assoc. 1999;214(5):651-659.

33. Calvo G, Holden E, Reid J, et al. Development of a behaviour-based measurement tool with defined intervention level for assessing acute pain in cats. J Small Anim Pract. 2014;55(12):622-629.

34. Keating SCJ, Thomas AA, Flecknell PA, Leach MC. Evaluation of EMLA cream for preventing pain during tattooing of rabbits: changes in physiological, behavioural and facial expression responses. PLoS One. 2012;7(9):e44437.

35. Sotocinal SG, Sorge RE, Zaloum A, et al. The rat grimace scale: a partially automated method for quantifying pain in the laboratory rat via facial expressions. Mol Pain. 2011;7:55.

36. Langford DJ, Bailey AL, Chanda ML, et al. Coding of facial expressions of pain in the laboratory mouse. Nat Methods. 2010;7(6):U447-U452.

37. Yeates JW, Main DCJ. Assessment of positive welfare: a review. Vet J. 2008;175(3):293-300.

38. Boissy A, Manteuffel G, Jensen MB, et al. Assessment of positive emotions in animals to improve their welfare. Physiol Behav. 2007;92(3): 375-397.

39. Mendl M, Burman OHP, Parker RMA, Paul ES. Cognitive bias as an indicator of animal emotion and welfare: emerging evidence and underlying mechanisms. Appl Anim Behav Sci. 2009;118(3-4):161-181.

40. Edgar J, Mullan S, Pritchard J, MacFarlane U, Main DCJ. Towards a 'Good Life' for farm animals: development of a resource tier framework to achieve positive welfare for laying hens. Animals. 2013;3: 584-605.

41. McMillan FD. Maximizing quality of life in III animals. J Am Anim Hosp Assoc. 2003;39(3):227-235.

42. Christiansen SB, Forkman B. Assessment of animal welfare in a veterinary context - a call for ethologists. Appl Anim Behav Sci. 2007;106(4): 203-220.

43. Wiseman-Orr ML, Nolan AM, Reid J, Scott EM. Development of a questionnaire to measure the effects of chronic pain on health-related quality of life in dogs. Am J Vet Res. 2004;65(8):1077-1084.

44. Mullan S, Main D. Preliminary evaluation of a quality-of-life screening programme for pet dogs. J Small Anim Pract. 2007;48(6):314-322.

45. Wojciechowska JI, Hewson CJ, Stryhn H, Guy NC, Patronek GJ, Timmons V. Development of a discriminative questionnaire to assess nonphysical aspects of quality of life of dogs. Am JVet Res. 2005;66(8): $1453-1460$

46. Davies M. Geriatric screening in first opinion practice - results from 45 dogs. J Small Anim Pract. 2012;53(9):507-513.

47. Freeman LM, Rush JE, Farabaugh AE, Must A. Development and evaluation of a questionnaire for assessing health-related quality of life in dogs with cardiac disease. J Am Vet Med Assoc. 2005;226(11): $1864-1868$. 
48. Wojciechowska JI, Hewson CJ, Stryhn H, Guy NC, Patronek GJ, Timmons V. Evaluation of a questionnaire regarding nonphysical aspects of quality of life in sick and healthy dogs. Am J Vet Res. 2005;66(8):1461-1467.

49. Yazbek KVB, Fantoni DT. Validity of a health-related quality-of-life scale for dogs with signs of pain secondary to cancer. J Am Vet Med Assoc. 2005;226(8):1354-1358.

50. Veissier I, Botreau R, Perny P. Multicriteria evaluation applied to farm animal welfare: difficulties and solutions from the Welfare Quality (R) project. Prod Anim. 2010;23(3):269-283.

51. Budke CM, Levine JM, Kerwin SC, Levine GJ, Hettlich BF, Slater MR. Evaluation of a questionnaire for obtaining owner-perceived, weighted quality-of-life assessments for dogs with spinal cord injuries. J Am Vet Med Assoc. 2008;233(6):925-930.

52. Yeates J, Main D. Assessment of companion animal quality of life in veterinary practice and research. J Small Anim Pract. 2009;50(6): 274-281.

53. Favrot C, Linek M, Mueller R, Zini E. Int Task Force Canine Atopic D. Development of a questionnaire to assess the impact of atopic dermatitis on health-related quality of life of affected dogs and their owners. Vet Dermatol. 2010;21(1):63-69.
54. Wiseman-Orr ML, Scott EM, Reid J, Nolan AM. Validation of a structured questionnaire as an instrument to measure chronic pain in dogs on the basis of effects on health-related quality of life. Am J Vet Res. 2006;67(11):1826-1836.

55. German AJ, Holden SL, Wiseman-Orr ML, et al. Quality of life is reduced in obese dogs but improves after successful weight loss. Vet J. 2012;192(3):428-434.

56. Levine GJ, Levine JM, Budke CM, et al. Description and repeatability of a newly developed spinal cord injury scale for dogs. Prev Vet Med. 2009;89(1-2):121-127.

57. Freeman LM, Rush JE, Oyama MA, et al. Development and evaluation of a questionnaire for assessment of health-related quality of life in cats with cardiac disease. J Am Vet Med Assoc. 2012;240(10):1188-1193.

58. Yeates JW, Mullan S, Stone M, Main DCJ. Promoting discussions and decisions about dogs' quality-of-life. J Small Anim Pract. 2011;52(9):459-463.

59. PROQOLID. 2015; Available from: http://www.proqolid.org/. Accessed February 4, 2015.

60. Snyder CF, Aaronson NK, Choucair AK, et al. Implementing patientreported outcomes assessment in clinical practice: a review of the options and considerations. Qual Life Res. 2012;21(8):1305-1314.
Veterinary Medicine: Research and Reports

\section{Publish your work in this journal}

Veterinary Medicine: Research and Reports is an international, peer-reviewed, open access journal publishing original research, case reports, editorials, reviews and commentaries on all areas of veterinary medicine. The manuscript management system is completely online and includes a very quick and fair peer-review system.

\section{Dovepress}

Visit http://www.dovepress.com/testimonials.php to read real quotes from published authors. 